\title{
Low temperature metalorganic chemical vapor deposition of conformal silver coatings for applications in high aspect ratio structures
}

Citation for published version (APA):

Eisenbraun, E. T., Klaver, A., Patel, Z., Nuesca, G., \& Kaloyeros, A. E. (2001). Low temperature metalorganic chemical vapor deposition of conformal silver coatings for applications in high aspect ratio structures. Journal of Vacuum Science and Technology, B, 19(2), 585-588. https://doi.org/10.1116/1.1349208

DOI:

10.1116/1.1349208

Document status and date:

Published: 01/01/2001

\section{Document Version:}

Publisher's PDF, also known as Version of Record (includes final page, issue and volume numbers)

\section{Please check the document version of this publication:}

- A submitted manuscript is the version of the article upon submission and before peer-review. There can be important differences between the submitted version and the official published version of record. People interested in the research are advised to contact the author for the final version of the publication, or visit the $\mathrm{DOI}$ to the publisher's website.

- The final author version and the galley proof are versions of the publication after peer review.

- The final published version features the final layout of the paper including the volume, issue and page numbers.

Link to publication

\footnotetext{
General rights

- You may freely distribute the URL identifying the publication in the public portal. follow below link for the End User Agreement:

www.tue.nl/taverne

Take down policy

If you believe that this document breaches copyright please contact us at:

openaccess@tue.nl

providing details and we will investigate your claim.
}

Copyright and moral rights for the publications made accessible in the public portal are retained by the authors and/or other copyright owners and it is a condition of accessing publications that users recognise and abide by the legal requirements associated with these rights.

- Users may download and print one copy of any publication from the public portal for the purpose of private study or research.

- You may not further distribute the material or use it for any profit-making activity or commercial gain

If the publication is distributed under the terms of Article 25fa of the Dutch Copyright Act, indicated by the "Taverne" license above, please 


\title{
Low temperature metalorganic chemical vapor deposition of conformal silver coatings for applications in high aspect ratio structures
}

\author{
Eric T. Eisenbraun, ${ }^{\text {a) }}$ Arjen Klaver, Zubin Patel, Guillermo Nuesca, \\ and Alain E. Kaloyeros \\ The New York State Center for Advanced Thin Film Technology and The Department of Physics Albany, \\ New York 12203
}

(Received 8 September 2000; accepted 18 December 2000)

\begin{abstract}
A low temperature metalorganic chemical vapor deposition process has been developed for the growth of conformal silver coatings for applications in reflective mirror arrays, computer chip metallization, and superconducting wire and cable technologies. The process employed the silver source precursor $\mathrm{Ag}(\mathrm{COD}) \mathrm{hfac}$, where $\mathrm{COD}=1,5$-cyclooctadiene and hfac $=1,1,1,5,5,5$-hexafluoro 2,4-pentanedionate. Silver films were deposited at wafer temperature, source temperature, and processing pressure in the range of, respectively, $160-240{ }^{\circ} \mathrm{C}, 80-150{ }^{\circ} \mathrm{C}$, and $0.5-5$ Torr. Experiments were carried out in the presence of either argon or hydrogen as coreactant. The resulting films were characterized by Rutherford backscattering spectrometry, x-ray photoelectron spectroscopy, x-ray diffraction, and cross-section scanning electron microscopy. These investigations indicated that the silver films were pure, highly specular, and exhibited excellent conformality in $180 \mathrm{~nm}$ wide trench structures with 7:1 aspect ratio. (c) 2001 American Vacuum Society. [DOI: 10.1116/1.1349208]
\end{abstract}

Silver possesses the lowest resistivity $(1.59 \mu \Omega \mathrm{cm})$, highest thermal conductivity $(430 \mathrm{~W} / \mathrm{m} \mathrm{K})$, and best optical reflectivity (97\% at a wavelength of $1000 \mathrm{~nm}$ ) of all metals. ${ }^{1}$ As a result, conformal silver coatings have generated significant interest for potential applications in microoptoelectromechanical systems, reflective mirror arrays, computer chip metallization, ${ }^{2}$ and superconducting wire and cable technologies. ${ }^{3}$ Silver films can be grown by many techniques, including sol-gel, ${ }^{4}$ evaporation, and sputtering. ${ }^{5}$ However, the need for highly conformal coatings in most of these applications has provided an important impetus for the development of a low temperature chemical vapor deposition (CVD) process for the growth of pure silver films that can uniformly coat the complex geometries associated with aggressive device and component topographies.

Initial research and development activities for CVD Ag were hindered by the observed chemical instability of most of the early metalorganic Ag precursors. ${ }^{6,7}$ This instability was attributed to some undesirable intrinsic properties of many silver complexes, including extreme sensitivity to light and moisture, and a tendency to oligomerize, thus making gas phase transport quite difficult. ${ }^{8}$

As a result, a significant body of work has gone into development of high vapor pressure silver sources that are stable during transport, handling, and gas phase delivery. In particular, ligand-stabilized $\mathrm{Ag}^{\mathrm{I}} \beta$-diketonates such as (hfac)Ag(VTES), where $\mathrm{hfac}=1,1,1,5,5,5$-hexafluoro-2,4pentanedionato and $\mathrm{VTES}=$ vinyltriethylsilane have been synthesized and employed for CVD Ag applications. ${ }^{9}$ These precursors tend to possess lower volatilities that their copper analogs, owing to the larger ionic radius of $\mathrm{Ag}$ as compared

a) Author to whom correspondence should be addressed; electronic mail: eeisenbraun@uamail.albany.edu to $\mathrm{Cu}^{7}$ In addition, various groups have demonstrated the ability to grow silver films with a purity degree higher than 99\% using a variety of metalorganic precursors such as silver trifluoroacetate and silver acetate. ${ }^{10}$ As mentioned above, one primary challenge for adaptation of silver carboxylates was their low volatility due to a tendency to dimerize in the gas phase. Furthermore, while the purity of the CVD silver films was discussed in those articles, no results were presented for the deposition of conformal silver coatings in high aspect ratio patterned structures.

The present investigators have identified the ligand stabilized silver source, $\mathrm{Ag}^{(\mathrm{I})}(\mathrm{COD})$ hfac, where COD $=1,5$-cyclooctadiene and $\mathrm{hfac}=1,1,1,5,5,5$-hexafluoro 2,4 pentanedionate, as a manufacturing-worthy source for CVD Ag. Its advantages include higher volatility compared to other metalorganic silver sources and good thermal stability during transport and handling. In addition, unlike its ligandstabilized copper(I) $\beta$-diketonate analogs, which typically require a metallic (conducting) surface to react via bimolecular disproportionation to form pure copper, ${ }^{11}$ the $\mathrm{Ag}^{(\mathrm{I})}(\mathrm{COD})$ hfac source tends to dissociate via direct decomposition. ${ }^{12}$ As such, it is highly amenable to the clean breakage of the silver-ligand bonds at low temperature on both conducting and insulating surfaces, leading to the deposition of pure Ag. In this article, results are presented from the successful application of the $\mathrm{Ag}^{(\mathrm{I})}(\mathrm{COD})$ hfac source for the growth of pure highly specular silver films with excellent conformality in $180 \mathrm{~nm}$ wide trench structures with 7:1 aspect ratio.

Depositions were carried out in a $200 \mathrm{~mm}$ capable custom designed warm-wall CVD system, shown schematically in Fig. 1. The Ag source precursor was loaded into a high vacuum reservoir in an inert ambient glove box, and the reservoir was then attached to the CVD reactor. The latter 


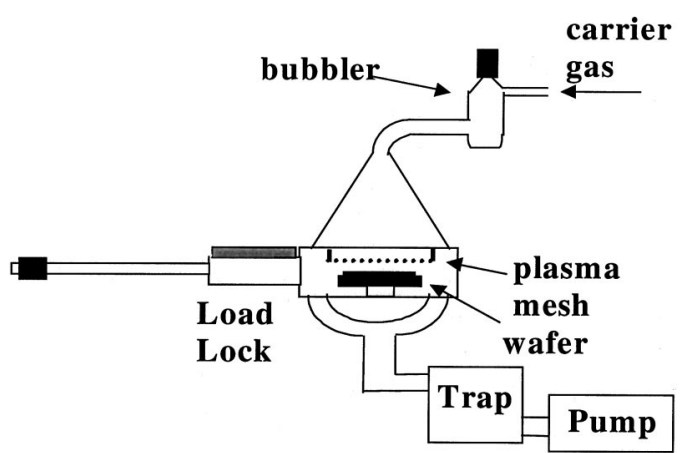

FIG. 1. Schematic diagram of the $200 \mathrm{~mm}$ wafer capable system used for the growth of CVD Ag films.

was outfitted with a high vacuum loadlock for sample transfer without chamber exposure to air, and was equipped with a plasma capability to allow in situ predeposition sample cleaning. Argon carrier gas flow was then initiated at 150 sccm through the precursor reservoir, followed by the introduction of the hydrogen gas directly into the CVD chamber. In this way, the precursor and hydrogen flows were kept separate to prevent any premature interactions that could result in the spontaneous decomposition of the $\mathrm{Ag}$ source in the presence of hydrogen. The hydrogen flow was varied in the range from 200 to $1000 \mathrm{sccm}$. Silver growth was started after the reservoir was heated to the precursor sublimation temperature. Sublimation temperatures in the range from 80 to $150^{\circ} \mathrm{C}$ were explored, in order to establish tight control metrics for precursor flux into the chamber. Various type substrates were used, including unpatterned silicon $(\mathrm{Si})$, thermally grown silicon dioxide $\left(\mathrm{SiO}_{2}\right)$, tungsten $(\mathrm{W})$, and tungsten nitride $\left(\mathrm{W}_{2} \mathrm{~N}\right)$, as well as $\mathrm{SiO}_{2}$ wafers that were patterned with $150 \mathrm{~nm}$ wide and $1.3 \mu \mathrm{m}$ deep trench structures.

In addition to gas flows and precursor temperatures discussed above, a wide range of other CVD silver processing variables were explored in this work. In particular, substrate temperatures were varied from 160 to $300^{\circ} \mathrm{C}$, and processing pressures varied from 0.5 to 5 Torr.

The resulting films were characterized by Rutherford backscattering spectrometry (RBS), x-ray photoelectron spectroscopy (XPS), x-ray diffraction (XRD), and crosssection scanning electron microscopy (SEM). These studies indicated that the microchemical and microstructural properties of the silver films were essentially identical for the cases of hydrogen and argon. This finding supports the expectation that the $\mathrm{Ag}^{(\mathrm{I})}(\mathrm{COD})$ hfac source is highly amenable to clean decomposition via direct dissociation of the silver-ligand bonds at low temperature on both conducting and insulating surfaces. The net outcome is the deposition of pure Ag, with less than 1 at. \% each carbon and fluorine incorporation.

The silver films grown within the entire process window investigated were metallic, continuous, and specular. RBS and XPS measurements were used to determine film purity. RBS spectra were taken with a $2 \mathrm{MeV} \mathrm{He}^{+}$beam, with gold and carbon samples used as calibration standards. Analyses of the silver films, as shown in Fig. 2 for a $70 \mathrm{~nm}$ thick $\mathrm{Ag}$ film deposited on $\mathrm{Si}$, show a pure silver phase that is free of

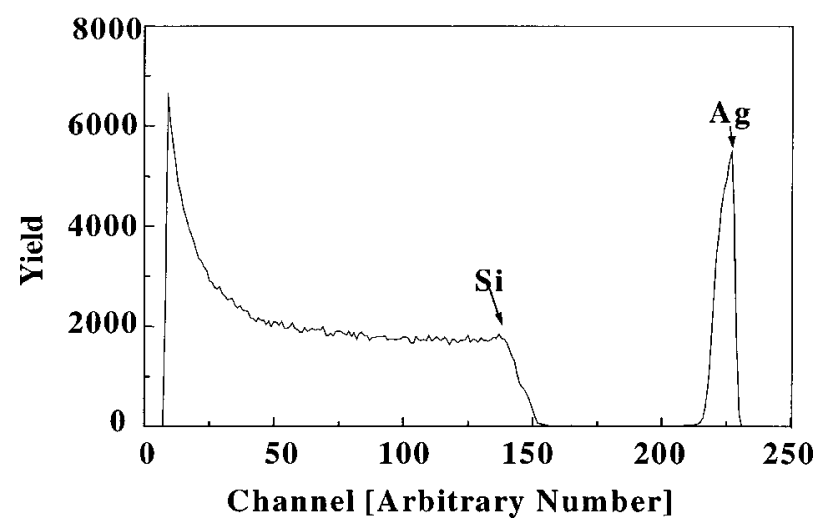

FIG. 2. Typical RBS spectrum of $70 \mathrm{~nm}$ thick CVD Ag film deposited on $\mathrm{Si}$.

heavy element contaminants within the detection limits of RBS (i.e., $<1$ at. $\%$ for elements with atomic number of 20 or higher).

XPS was performed using a PHI model 5600 Multitechnique system with a spherical capacitor analyzer and sputteretch capability for compositional depth profiling. The primary $\mathrm{x}$-ray beam was generated using a $\mathrm{Mg} k \alpha$ x-ray source, operating at $300 \mathrm{~W}$ and $15 \mathrm{kV}$. XPS measurements of CVD films deposited on $\mathrm{SiO}_{2}$ (Fig. 3) further supported the existence of a pure Ag film. Fluorine (F), carbon (C), and oxygen (O) contamination, which resulted from film exposure to ambient conditions during transport to the XPS system, were limited to the film top surface. Within the sensitivity of XPS, no measurable fluorine or carbon levels were detected in the film, while oxygen concentrations were approximately $\sim 3$ at. $\%$.

The microstructure and conformality of the CVD Ag films were examined with SEM, using a Hitachi S-4000 field emission microscope with a $15-20 \mathrm{kV}$ primary beam voltage. These investigations indicated that the growth temperature had a strong effect on film morphology and grain size. In this respect, Figs. 4(a)-4(c) present SEM micrographs of $70 \mathrm{~nm}$ thick $\mathrm{Ag}$ films deposited on thermally grown $\mathrm{SiO}_{2}$ substrates. As can be seen from Figs. 4(a) and 4(b), surface grain size and corresponding surface roughness were similar for all films deposited below $200^{\circ} \mathrm{C}$. However, a marked

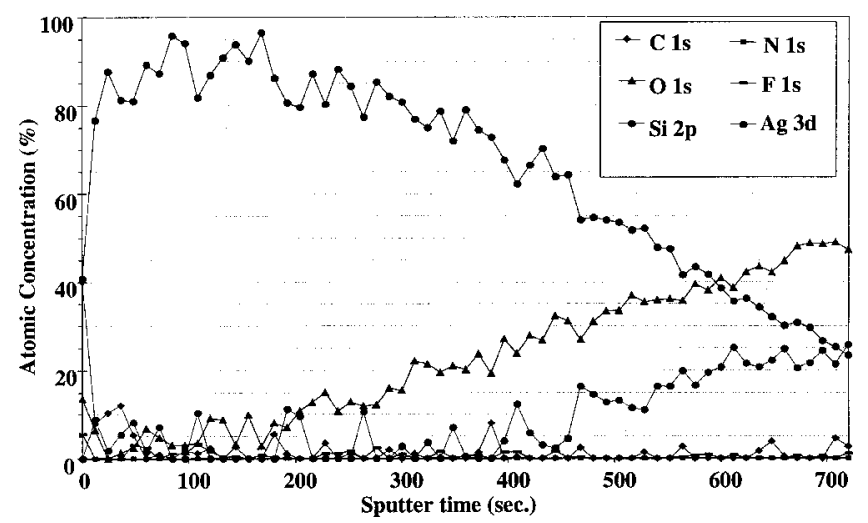

FIG. 3. Typical XPS depth profile of $70 \mathrm{~nm}$ thick CVD Ag film deposited on $\mathrm{SiO}_{2}$. 

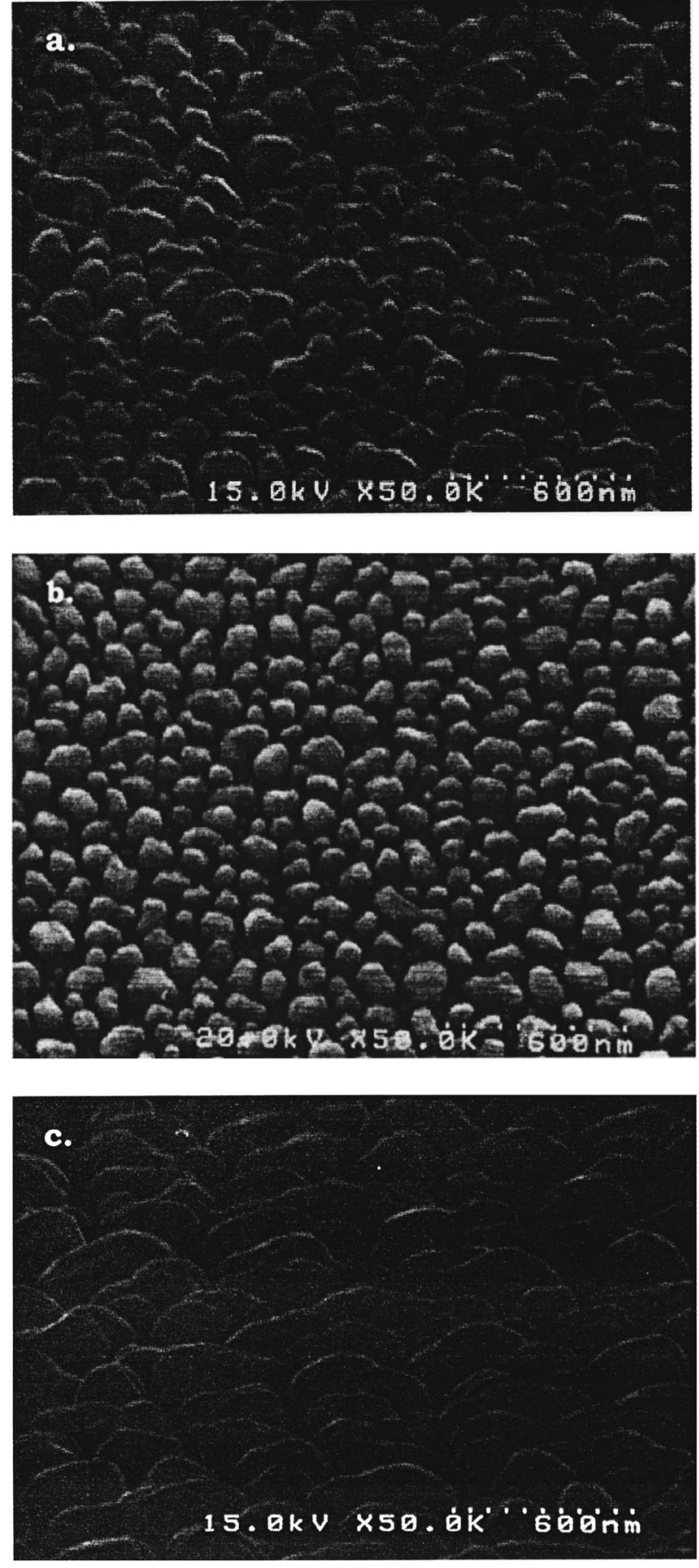

FIG. 4. (a) Surface morphology of a $70 \mathrm{~nm}$ thick CVD Ag film deposited on blanket oxide substrate at $160^{\circ} \mathrm{C}$. (b) Surface morphology of a $70 \mathrm{~nm}$ thick CVD Ag film deposited on blanket oxide substrate at $200^{\circ} \mathrm{C}$. (c) Surface morphology of a $70 \mathrm{~nm}$ thick CVD Ag film deposited on blanket oxide substrate at $240{ }^{\circ} \mathrm{C}$.

increase in surface grain size and associated surface roughness were detected as the substrate temperature was raised above $200^{\circ} \mathrm{C}$ [Fig. 4(c)].

Furthermore, CVD Ag film step coverage was examined as a function of substrate temperature in the range from 160 to $240^{\circ} \mathrm{C}$ in $180 \mathrm{~nm}$ wide, $7: 1$ aspect ratio patterned oxide structures. Conformality was found to be better than $80 \%$

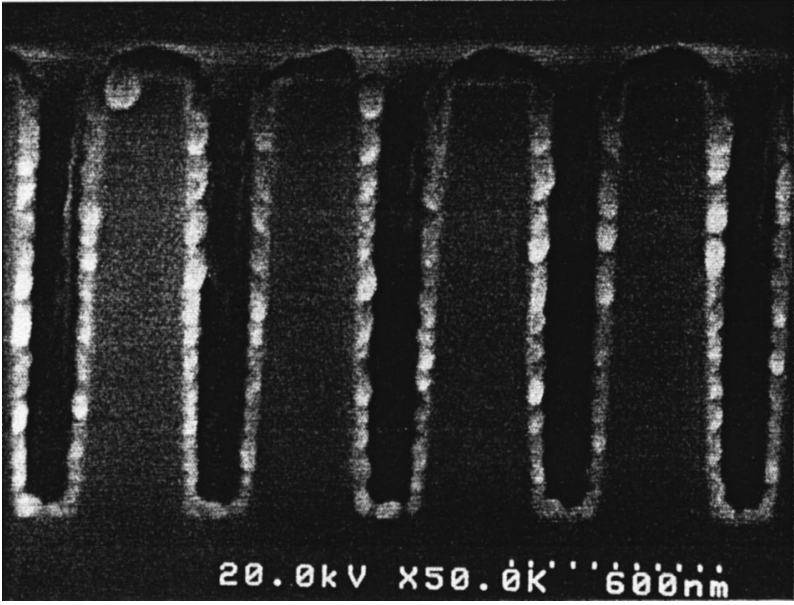

FIG. 5. Typical thickness profile for a CVD Ag film deposited on patterned oxide substrate at $200^{\circ} \mathrm{C}$.

across the entire temperature window investigated. Figure 5 is a representative scanning electron micrograph of a representative CVD silver film deposited at a wafer temperature of $200{ }^{\circ} \mathrm{C}$

Film microstructure was further characterized by XRD. In this respect, Fig. 6 displays an XRD spectrum of a $70 \mathrm{~nm}$ thick CVD Ag film deposited on $\mathrm{SiO}_{2}$ at $200^{\circ} \mathrm{C}$. XRD analysis indicated a polycrystalline phase, with a predominantly $\langle 111\rangle$ oriented texture.

In summary, a low temperature CVD process has been developed for the growth of $\mathrm{Ag}$ films using $\mathrm{Ag}(\mathrm{COD}) \mathrm{hfac}$ as source precursor across a wide processing window that included wafer temperature, source temperature, and processing pressure in the range of, respectively, $160-240^{\circ} \mathrm{C}$, $80-150^{\circ} \mathrm{C}$, and $0.5-5$ Torr. The Ag films were found to be pure, highly specular, and exhibited excellent conformality in $180 \mathrm{~nm}$ wide trench structures with 7:1 aspect ratio.

In summary, a low temperature metalorganic CVD silver process has been developed which has been demonstrated to yield pure Ag films with excellent conformality in aggressive patterned structures.

This work was supported in part by the New York State Center for Advanced Thin film Technology (CAT) and Nanocrystal Imaging Corporation. This support is gratefully acknowledged.

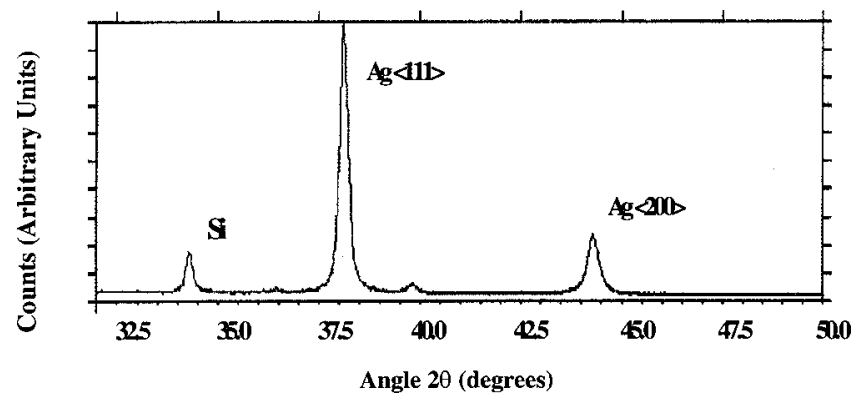

FIG. 6. Typical x-ray diffraction spectrum of CVD Ag film deposited on $\mathrm{SiO}_{2}$ 
${ }^{1}$ Handbook of the Physicochemical Properties of the Elements, edited by G. V. Samsonov (IFI-Plenum, New York, 1968).

${ }^{2}$ See, for example, T. Baum and P. Comita, The Chemistry of Metal CVD (VCH, New York, 1994).

${ }^{3}$ See, for example, M. Kuwarbara and N. Kusaka, Jpn. J. Appl. Phys., Part 2 27, L1504 (1988).

${ }^{4}$ X. Qin, W. Zhang, L. Zhang, D. Jiang, X. J. Liu, and D. Jin, Phys. Rev. B 56, 10596 (1997).

${ }^{5}$ K. Chiu, M. Blamire, and Z. Barber, J. Vac. Sci. Technol. A 17, 2891 (1999).

${ }^{6}$ A. Bailey, T. Corbitt, M. Hampden-Smith, E. Duesler, and T. Kodas, Polyhedron 12, 1785 (1993).
${ }^{7}$ G. Doyle, K. Eriksen, and D. Van Engen, Organometallics 4, 830 (1985).

${ }^{8}$ See, for example, P. Jeffries, S. Wilson, and G. Girolami, J. Organomet. Chem. 449, 203 (1993).

${ }^{9}$ K. Chi, K. Chen, S. Peng, and G. Lee, Organometallics 15, 2575 (1996).

${ }^{10}$ W. Partenheimer and E. Johnson, Inorg. Chem. 12, 1274 (1973).

${ }^{11}$ See, for example, T. Baum and C. Larson, J. Electrochem. Soc. 140, 154 (1993).

${ }^{12}$ M. Shapiro, Chemical Vapor Deposition of Silver Films for Superconducting Wire Applications (UMI Diss. Inform. Serv., No. 9124543, 1992). 